\title{
Perspective
}

\section{The Role of Structured Carbon in Downsized Transition Metal-Based Electrocatalysts toward a Green Nitrogen Fixation}

\author{
Marcello Ferrara $^{1}\left(\mathbb{D}\right.$, Michele Melchionna ${ }^{1}\left(\mathbb{D}\right.$, Paolo Fornasiero ${ }^{1,2}\left(\mathbb{D}\right.$ and Manuela Bevilacqua ${ }^{2,3, *(D)}$ \\ 1 Department of Chemical and Pharmaceutical Sciences, University of Trieste and Consortium INSTM, \\ 34127 Trieste, Italy; marcello.ferrara@phd.units.it (M.F.); melchionnam@units.it (M.M.); \\ pfornasiero@units.it (P.F.) \\ 2 Department of Chemical and Pharmaceutical Sciences, Institute of Chemistry of OrganoMetallic \\ Compounds (ICCOM-CNR), University of Trieste, 34127 Trieste, Italy \\ 3 Institute of Chemistry of OrganoMetallic Compounds (ICCOM-CNR), via Madonna del Piano 10, \\ 50019 Sesto Fiorentino, Italy \\ * Correspondence: mbevilacqua@iccom.cnr.it
}

check for updates

Citation: Ferrara, M.; Melchionna, M.; Fornasiero, P.; Bevilacqua, M. The Role of Structured Carbon in

Downsized Transition Metal-Based Electrocatalysts toward a Green Nitrogen Fixation. Catalysts 2021, 11, 1529. https://doi.org/10.3390/ catal11121529

Academic Editor: Konstantinos D. Vogiatzis

Received: 15 November 2021 Accepted: 9 December 2021 Published: 15 December 2021

Publisher's Note: MDPI stays neutral with regard to jurisdictional claims in published maps and institutional affiliations.

Copyright: (c) 2021 by the authors. Licensee MDPI, Basel, Switzerland. This article is an open access article distributed under the terms and conditions of the Creative Commons Attribution (CC BY) license (https:/ / creativecommons.org/licenses/by/ $4.0 /)$.

\begin{abstract}
Electrocatalytic Nitrogen Reduction Reaction (NRR) to ammonia is one of the most recent trends of research in heterogeneous catalysis for sustainability. The stark challenges posed by the NRR arise from many factors, beyond the strongly unfavored thermodynamics. The design of efficient heterogeneous electrocatalysts must rely on a suitable interplay of different components, so that the majority of research is focusing on development of nanohybrids or nanocomposites that synergistically harness the NRR sequence. Nanostructured carbon is one of the most versatile and powerful conductive supports that can be combined with metal species in an opportune manner, so as to guide the correct proceeding of the reaction and boost the catalytic activity.
\end{abstract}

Keywords: nitrogen reduction reaction; carbon-based electrocatalysts; structured carbon

\section{Introduction}

The electrochemical conversion of the nitrogen molecule to the high-value ammonia product nowadays represents an interesting strategy to face the increasing world demand for a wide range of applications, starting from agricultural fertilizers to the challenging field of energy storage. To this day, the Haber-Bosch method represents one of the most important leaps in industrial chemistry and has allowed society to gain momentum during the industrial revolution [1]. An analysis from the Institute of Industrial Productivity reported in Chemical and Engineering News in 2019 stated in the title: "Industrial ammonia production emits more $\mathrm{CO}_{2}$ than any other chemical-making reaction. Chemists want to change that" [2]. Actually, in evaluating the impact of this reaction on the environment, one needs to focus not only on the energy required to sustain high temperature and pressure. In fact, the hydrogen used in the process is historically derived from steam reforming (SMR) and the water gas shift reaction (WGSR). Nowadays, the ammonia synthesis process accounts for over $1 \%$ of the world's energy needs, and this figure is not expected to shrink any time soon [3]. Research is then focused on different strategies that rely on lower pressure and lower temperature processes [4,5], on hybrid designs with electrochemical production of hydrogen combined to the Haber-Bosch process [6], and finally, on the electrochemical Nitrogen Reduction Reaction (NRR). With the growing interest in NRR catalysts capable of high selectivity (i.e., able to suppress the Hydrogen Evolution Reaction (HER) at the cathode), carbon-based electrodes gained attention thanks to their low cost and versatility, both as an active catalyst and as a support. In particular, stabilization of the active site is of paramount importance in these kinds of materials, given the reliance on intrinsically unstable structures such as defects sites, unusual facets, or single-atom catalysts $[7,8]$. A vast number of studies have been carried out centered on this key topic, 
ranging from the more classical approach of $\mathrm{N}$ - or B-monodoped porous carbon materials (common to the field of $\mathrm{CO}_{2} \mathrm{RR}$ and ORR reactions) [9-13] to the more complex co-doping heteroatom strategy [14-17], and furthermore to tunable edge sites and topological intrinsic defects in the carbon matrix (as schematized in Figure 1). From this perspective, we will explore current use of carbon-based materials, and the design challenges it represents, while paving the way for future exploration on material engineering for the next generation of $\mathrm{N}_{2}$ reduction catalysts.

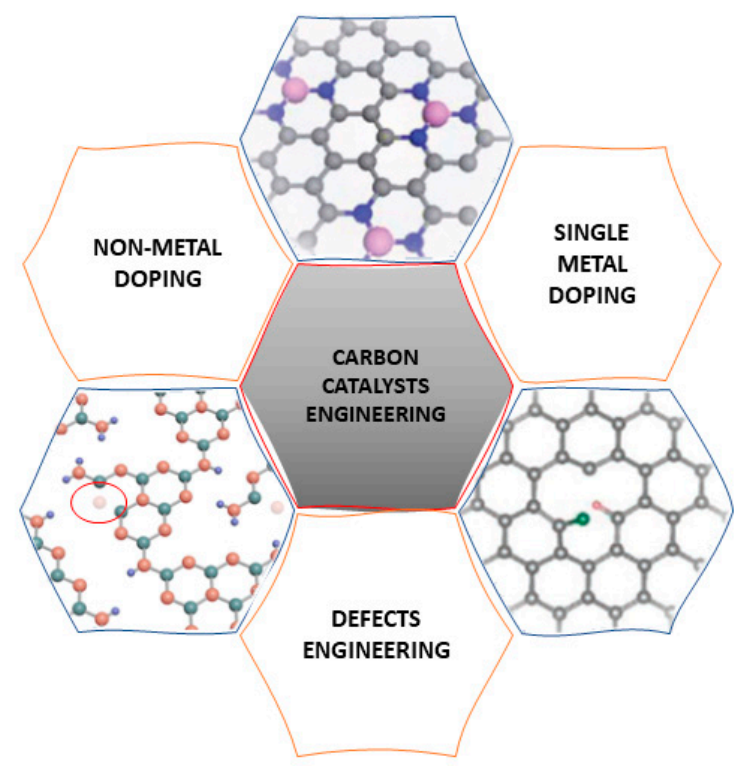

Figure 1. Relevant techniques for carbon catalyst activation and their main combinations.

\section{Electrocatalysts Design: The Key Aspects}

Aqueous environment (that includes acidic, basic, or neutral solutions) represents the most widely adopted electrolyte that exploits the $\mathrm{H}^{+}$or $\mathrm{OH}^{-}$charge carriers. Stable materials in this reaction media comprise many types of different $\mathrm{N}_{2}$ electrocatalysts, including transition metal-based materials (alloys, nitrides, sulfides, oxides, etc.), but also other classes, including heteroatom-doped metal-free carbon nano-textures and singleatom catalysts (SACs), where generally the doped carbon functions as support for the single-metal site. Sifting through the state-of-the-art, two main features emerged in the rational protocol plan for a promising $\mathrm{N}_{2}$ electrocatalyst design: (i) adequate surface area and porous structure, and (ii) the formation of suitable defects to promote $\mathrm{N}_{2}$ adsorption and conversion. It follows that heteroatom-doped (usually nitrogen or boron) carbon-based nanostructures (CNS) could represent a promising strategy to enhance NRR, given the wide range of existing CNS: the common carbon nanotubes (CNT), nano-horns (CNH), graphene and related structures (GO, rGO), but also more sophisticated materials such as carbon dots (CDs) are among the latest research frontiers in carbon-based nanomaterials due to fundamental features such as electrochemical high solubility in many solvents, large specific surface area and relevant edge sites for functionalization, low-cost ability for modification with attractive surface chemistry, and other modifiers/nanomaterials [18-23].

On the other hand, it is important to highlight that N-doped carbon catalysts could be subjected to degradation during the process, thus releasing ammonia into the electrolysis solution as an external source, not directly arising from NRR, affecting true activity evaluation. In consideration of all the other numerous difficulties in rigorously evaluating the activity of NRR catalysts [24], it is critical to perform required additional measurements [25], or have precise control of experimental parameters [26,27]. Nevertheless, N-doped carbon-based catalysts still represent one of the most investigated strategies: representative examples include a porous carbon material prepared by ZIF-8 treatment by Mukherjee et al. [28] and the N-doped carbon nanospikes (CNS) designed by Song et al. [29], as well as numerous 
graphene-based structures. Concerning graphene as a representative case study, it has been demonstrated by several studies that a main general requirement to enhance catalytic performance is to endow an adequate charge carrier mobility, so as to promote charge transfer during NRR combined with a high structural stability [30,31]. Many different theoretical studies on NRR (and also on other electrochemical reduction processes) have indeed focused on graphene as the nanocarbon phase, in particular for the class of SAC electrocatalysts [32-34].

\section{Electrocatalysts' Design: The Role of Carbon}

Analyzing the state-of-the-art concerning metal-free carbon-based electrocatalysts for NRR, the exploitation of OVs (Oxygen Vacancies) and NVs (Nitrogen Vacancies) [35], as well as CVs (Carbon Vacancies) (Figure 2), emerged as the main key concept to extensively investigate the role of carbon and its NRR catalytic properties. The potential activity of carbon is most exemplified in the case of the Defective reduced Graphene Oxide (DrGO)based electrocatalyst with engineered defects, reported by Zhang et al. [36]. Through coupled experimental and computational analysis, the group was able to pin the high Faradaic Efficiencies (FEs) shown by the material ( $22.0 \%$ at $-0.116 \mathrm{~V}$ in acidic media, see Table 1) to the CVs created by the hydrothermal treatment, leading to unsaturated carbon sites (oxygen-containing functional groups, structural defects in the basal plane, and on edge sites). The computational part of the study showed, in particular, that ${ }^{*} \mathrm{~N}_{2}$ was most active on sites with a double CV (DrGO-DV), while on single CVs (DrGO-SV) and on terminal $-\mathrm{COOH}$ groups, the energetics where much less favorable toward $\mathrm{N}_{2}$ reduction.

(a)

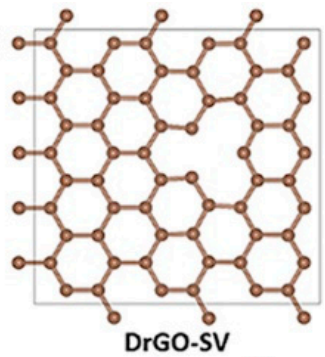

(b)

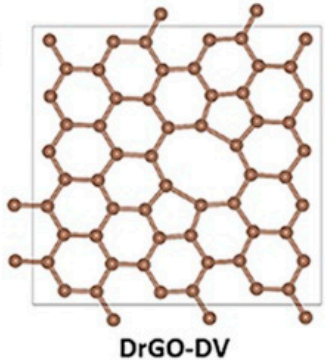

(c)

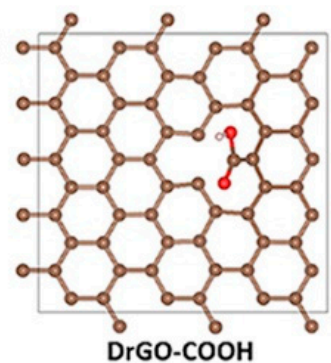

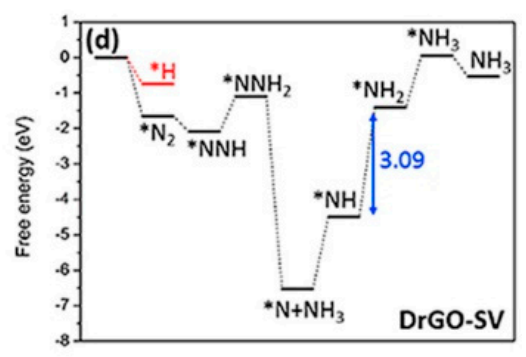
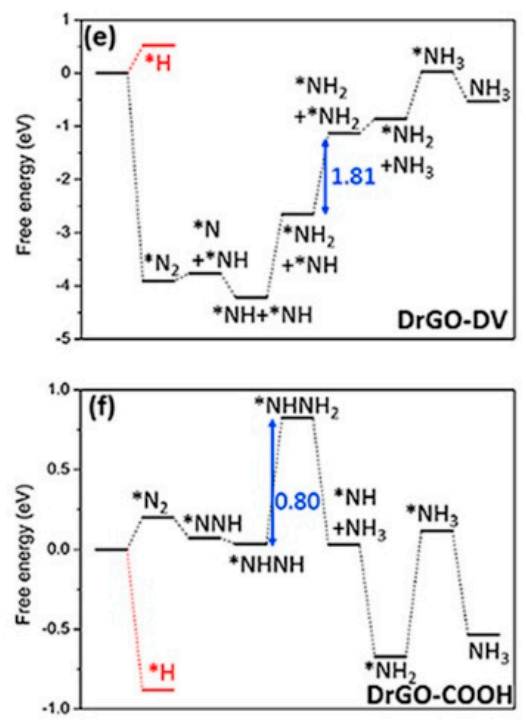

Figure 2. Different defects on DrGO: single Carbon Vacancy (a), double Carbon Vacancy (b), and carboxylic carbon (c). Energetics for main NRR intermediates on these defects are reported on the right side (d-f). Reprinted with permission from [36]. Copyright 2019 Elsevier Ltd. 
Table 1. Carbon-based catalysts for NRR investigated in this review and their main catalytic parameters (ammonia formation rate and Faradaic Efficiency (FE)).

\begin{tabular}{|c|c|c|c|c|c|}
\hline Catalyst & Electrolyte & Potential/V vs. RHE & $\begin{array}{c}\text { Rate/ } \\
\mu_{\mathrm{NH} 3} \mathrm{H}-1 \mathrm{mg}_{\text {cat }}-1\end{array}$ & $\begin{array}{l}\text { FE/ } \\
\%\end{array}$ & \\
\hline N-DOPED CARBON & $0.1 \mathrm{M} \mathrm{KOH}$ & -0.3 & $70.8+$ & 10.2 & [28] \\
\hline N-DOPED CARBON NANOSPIKES & $0.25 \mathrm{M} \mathrm{LiClO}_{4}$ & -1.19 & $97.18 *$ & 11.56 & [29] \\
\hline S-, B-DOPED CARBON NANOFIBERS & $0.5 \mathrm{M} \mathrm{K}_{2} \mathrm{SO}_{4}{ }^{\mathrm{T}}$ & -0.7 & $3.79 *$ & 22.4 & [31] \\
\hline DEFECTIVE RGO & $0.1 \mathrm{M} \mathrm{HCl}$ & -0.116 & 7.1 & 22 & [36] \\
\hline S-DOPED GRAPHENE & $0.1 \mathrm{M} \mathrm{HCl}$ & -0.6 & 27.3 & 11.5 & [37] \\
\hline FTO & Ionic liquid & -0.8 & $1.3 t^{*}$ & 30 & [38] \\
\hline B-DOPED GRAPHENE & $0.05 \mathrm{M} \mathrm{H}_{2} \mathrm{SO}_{4}$ & -0.5 & $49+$ & 10.8 & [39] \\
\hline F-DOPED CARBON & $0.05 \mathrm{M} \mathrm{H}_{2} \mathrm{SO}_{4}$ & -0.2 & 197.7 & 54.8 & [40] \\
\hline DEFECTIVE G-C3N4 & $0.1 \mathrm{M} \mathrm{HCl}$ & -0.2 & 8.09 & 11.59 & [41] \\
\hline AU1-C3N4 & $0.005 \mathrm{M} \mathrm{H}_{2} \mathrm{SO}_{4}$ & -0.1 & $1.96+$ & 11.1 & [42] \\
\hline RU SA/NC & $0.05 \mathrm{M} \mathrm{H}_{2} \mathrm{SO}_{4}$ & -0.2 & 120.9 & 29.6 & [43] \\
\hline MO SA/NPC & $0.1 \mathrm{M} \mathrm{KOH}$ & -0.3 & 34.0 & 14.6 & [44] \\
\hline ISAS-FE/NC & $0.1 \mathrm{M}$ PBS & -0.4 & 62.9 & 18.6 & [45] \\
\hline FE SA/NC & $0.1 \mathrm{M} \mathrm{KOH}$ & 0.0 & 7.48 & 56.55 & [46] \\
\hline
\end{tabular}

+ Calculated from reported values in the paper. ${ }^{*} \mu \mathrm{g}_{\mathrm{NH} 3} \mathrm{~h}^{-1} \mathrm{~cm}^{-2}$, for lack of data to calculate the mass normalized rate.

However, most publications make use of heteroatoms through non-metal and metal doping, to modulate the adsorption and desorption of NRR reaction intermediates and products by inducing charge and spin densities on $\mathrm{C}$ atoms and by enhancing the electron transfer. The carbon nanostructure's flexibility defines its main role as a support for most catalyst designs. Some representative examples are discussed here in more detail to better explain this concept.

\subsection{Case of Graphene (X-Doped) to Limit HER}

A wide range of experiments have been performed in both aqueous and non-aqueous electrolytes, such as ionic liquids, on transition metal-based but also metal-free X-doped carbon materials ( $\mathrm{X}=$ non-metal heteroatom). FE approximately above $10 \%$ (see Table 1 for data comparison) were reported in aqueous environment [37], while higher FE could be achieved in non-aqueous electrolytes [38] as a result of the much lower availability of protons and therefore the diminished competition with the HER process. There is no doubt that operating in aqueous environment represents the best manageable condition in view of a real application for the electrocatalyst, i.e., in ion-exchange PEM electrolyzers, as well as the most appealing choice from an environmental impact point of view [47].

Among various non-metal heteroatoms, the incorporation of $\mathrm{N}$ into graphene represents a common strategy to tailor the electronic properties of this carbon texture. Nitrogendoped graphene (N-graphene) has been demonstrated to find applications in energy storage and conversion [48,49], but also in the field of nano-electronic device design [50,51]. $\mathrm{N}$-graphene can be synthesized by using both a bottom-up method starting from Ncontaining precursors or through a post-treatment of graphene and graphite oxide (GO), introducing the $\mathrm{N}$ atoms as a final step. Despite being frequently investigated as a metalfree electrocatalyst in several processes such as ORR, HER, and $\mathrm{CO}_{2} \mathrm{RR}$ [52-55], in the case of NRR in aqueous electrolytes, it appears that inclusion of a transition metal active site, i.e., in the form of single atom, is imperative for obtaining promising activities. The combined properties of high charge-mobility (graphene component acting as an electronic reservoir) to the synergic metal- $\mathrm{N}$ active site for $\mathrm{N}_{2}$ bond breaking play a fundamental role for an efficient electrochemical $\mathrm{N}_{2}$ fixation [56].

Most recently, B-doped graphene in the form of nanosheets has been reported to be highly selective toward $\mathrm{N}_{2}$ reduction to ammonia, with the Faradaic Efficiencies exceeding $10 \%$ [39]. It has been proven that boron doping in the graphene texture results in a redistribution of electron density; therefore, it provides excellent active sites for $\mathrm{N}_{2}$ adsorption and the consequently enhancement of ammonia reduction. Moreover, the positively charged 
boron active sites can strongly inhibit the binding of protons (under acidic conditions) to disfavor the competing HER, thus providing high FE for ammonia formation. $\mathrm{N}_{2}$ reduction experiments showed that B-doped graphene was able to efficiently catalyze the formation of ammonia in acidic environment, with the maximum rate and FE reaching $1.6 \times 10^{-10} \mathrm{~mol} \mathrm{~s}^{-1} \mathrm{~cm}^{-2}$ and $10.8 \%$, respectively, at $-0.5 \mathrm{~V}$ vs. RHE (also see Table 1 for data comparison).

Another very recent example involved the use of the F-doped 3D porous carbon network synthesized by Liu et al. via a procedure consisting of crystallization of UiO-66 (a metal organic framework based on Zr nodes) in the presence of PTFE, pyrolysis, and final HF etching, leading to the metal-free F-doped carbon texture [40]. The resulting catalytic material showed outstanding NRR selectivity of $54.8 \%$ at $-0.2 \mathrm{~V}$ in $0.05 \mathrm{M} \mathrm{H}_{2} \mathrm{SO}_{4}$, by simultaneously suppressing $\mathrm{H}^{+}$reduction and promoting $\mathrm{N}_{2}$ activation near the $\mathrm{F}$ atom (Figure 3). In particular, the active site was assessed with DFT calculations and located on the 5 th carbon atoms on defective graphene slabs.
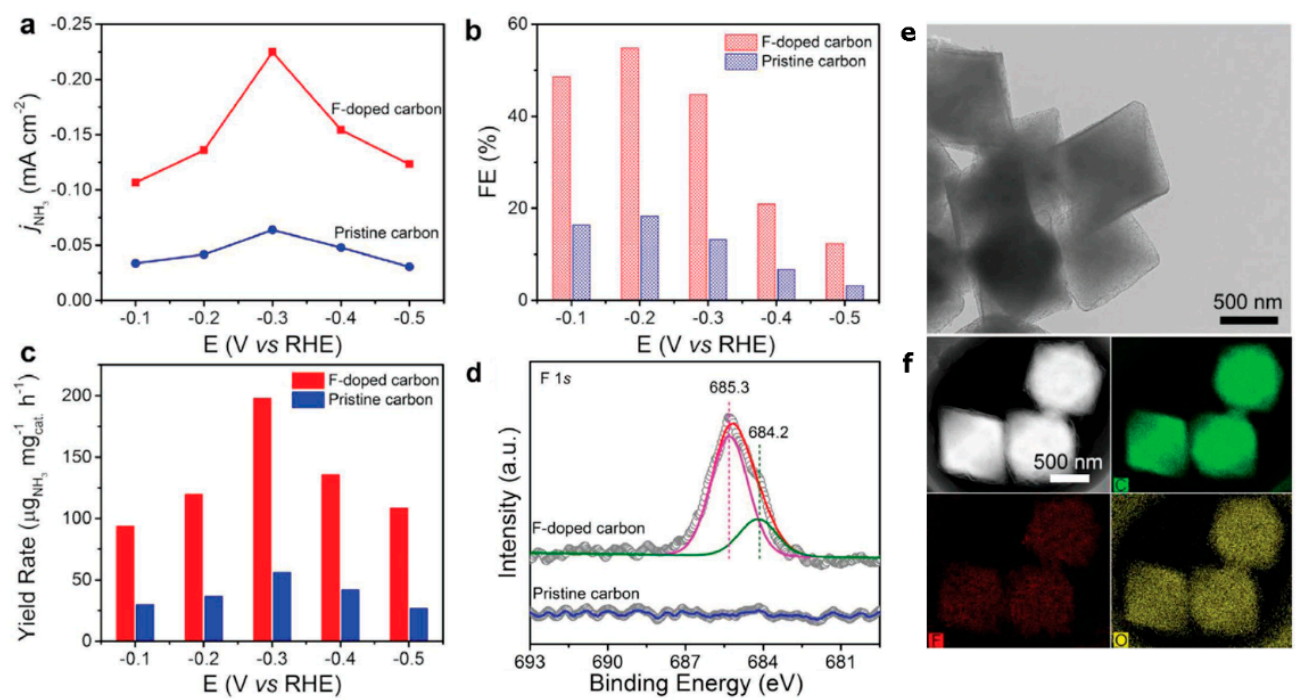

Figure 3. Current density for $\mathrm{NH}_{3}(\mathbf{a}), \mathrm{FE}(\mathbf{b})$, and yield rate for $\mathrm{NH}_{3}$ of F-doped carbon and pristine carbon at different applied potentials (c). Comparison of F 1s XPS spectra for F-doped carbon and pristine carbon (d), TEM (e), and HAADF-STEM images (f), and corresponding EDS elemental mapping results for F-doped carbon. Adapted with permission from [40]. Copyright 2020 WileyWHC Verlag and Co. KGaA Weinheim.

\subsection{Graphitic Carbon Nitride $\left(g-C_{3} N_{4}\right)$}

Graphitic carbon nitride $\left(\mathrm{g}-\mathrm{C}_{3} \mathrm{~N}_{4}\right)$ has been attracting increasing attention over recent years, coming to prominence for its many useful properties [57,58]. Importantly, its preparation is carried out by means of relatively simple strategies and starting from cheap precursors (most notably melamine and urea). It has shown great versatility as a metal-free photocatalyst [21,59-61] and in other non-photocatalytic processes, including electrocatalysis [62,63]. A first paper on $\mathrm{g}-\mathrm{C}_{3} \mathrm{~N}_{4}$ with $\mathrm{NVs}$ was published by Lv et al. [41], in which the defective $\mathrm{C}_{3} \mathrm{~N}_{4}$ showed uncharacteristic activity toward NRR $\left(8.09 \mu \mathrm{g} \mathrm{h}^{-1} \mathrm{mg}_{\text {cat }}{ }^{-1}\right.$, FE $11.6 \%$ at $-0.2 \mathrm{~V}$, see Table 1$)$, ten times higher than the pristine material $\left(0.74 \mu \mathrm{g} \mathrm{h}^{-1} \mathrm{mg}_{\text {cat }}{ }^{-1}\right.$ at the same potential). DFT calculations showed that after introducing a $\mathrm{NV}$ at the $\mathrm{N}_{2} \mathrm{C}$ site, $\mathrm{N}_{2}$ could adsorb on the $\mathrm{g}-\mathrm{C}_{3} \mathrm{~N}_{4}$ in the form of di-nuclear end-on coordinated mode. The electrons on adjacent carbon atoms are transferred to the adsorbed $\mathrm{N}_{2}$, namely an electron back-donation process, resembling what generally takes place in transition metals with $\mathrm{d}$-orbital electrons being donated to the $\pi \mathrm{N}-\mathrm{N}$ antibonding orbitals.

Although these results seem promising, it is still necessary to significantly boost the $\mathrm{NH}_{3}$ formation rate. To this end, many transition-metal SACs supported on $\mathrm{g}-\mathrm{C}_{3} \mathrm{~N}_{4}$ have been studied, mainly in theoretical publications. Chen et al. [64] worked on a series of 
single-metal atoms anchored onto the NVs in graphitic carbon nitride (Ti, Co, Mo, W, and $\mathrm{Pt}$ on $\mathrm{g}-\mathrm{C}_{34}$ ). Among these various TM metals, it was found that NRR proceeded smoothly on the single tungsten (W) atom anchored on a $\mathrm{g}-\mathrm{C}_{3} \mathrm{~N}_{4}$ monolayer via the associative enzymatic pathway, and a small negative potential of $-0.35 \mathrm{~V}$ can onset the $\mathrm{N}_{2}$ fixation, while suppressing the competing HER. Along this path, Wang et al. [42] synthetized an $\mathrm{Au}_{1}$ catalyst supported on $\mathrm{g}-\mathrm{C}_{3} \mathrm{~N}_{4}$ that showed an ammonia formation rate of $1305 \mu \mathrm{g} \mathrm{h}^{-1} \mathrm{mg}_{\mathrm{Au}}{ }^{-1}$ (Table 1), much higher (22.5×) than bulk Au nanoparticles supported on carbon nitride. DTF calculation results revealed that both $\mathrm{Au}_{1} / \mathrm{C}_{3} \mathrm{~N}_{4}$ and $\mathrm{Au}$ NPs $/ \mathrm{C}_{3} \mathrm{~N}_{4}$ proceed with an alternating hydrogenation mechanism, but the lower required energy on Au single atoms explains the enhanced $\mathrm{NH}_{4}{ }^{+}$formation and $\mathrm{FE}$ on $\mathrm{Au}_{1} / \mathrm{C}_{3} \mathrm{~N}_{4}$.

\section{3. $\mathrm{C}_{2} \mathrm{~N}$ Monolayer}

Another interesting example group based on carbon nanostructures for NRR is represented by nitrogenated holey graphene- $\mathrm{C}_{2} \mathrm{~N}$ monolayer support. Wang et al. investigated the series of $\mathrm{Zn}, \mathrm{Mo}, \mathrm{Ru}, \mathrm{Rh}, \mathrm{Pd}$, and $\mathrm{Ag}$ single transition-metal atoms supported on $\mathrm{C}_{2} \mathrm{~N}$ for NRR electrocatalysis [65]. The $\mathrm{C}_{2} \mathrm{~N}$ monolayer is constituted by 6-fold cavities, the corner of which is the most stable site for the attachment of a single transition-metal atom. Among all the catalysts, the Mo- $\mathrm{C}_{2} \mathrm{~N}$ monolayer appeared to be the most promising, as a result of the better stabilization of the ${ }^{*} \mathrm{~N}_{2} \mathrm{H}$ intermediate (i.e., a low overpotential for this key intermediate) and also because of the stronger adsorption of ${ }^{*} \mathrm{~N}_{2} \mathrm{H}$ with respect to that of ${ }^{*} \mathrm{H}$, thus resulting once again in the useful suppression of hydrogen evolution. $\mathrm{N}_{2}$ adsorbs on the Mo center in an end-on configuration, accompanied by an elongation of the $\mathrm{N}_{2}$ bond and a transfer of spin moment from the catalyst to the adsorbed $\mathrm{N}_{2}$ molecule. These results indicate that the $\mathrm{Mo}-\mathrm{C}_{2} \mathrm{~N}$ monolayer could significantly activate the $\mathrm{N}_{2}$ molecule.

\section{The Concept of Downsized TM-Electrocatalysts: From Single to Quadruple-Atoms Dispersed on Structured Carbon Types}

Following recent trends in nanoparticles synthesis, many efforts have been focusing on anchoring single TM atoms on different supports because of the overlap of their HOMOs with $\mathrm{N}_{2}$ LUMO. This overlap is instrumental to the weakening of the $\mathrm{N}-\mathrm{N}$ triple bond and is the first step to a competitive NRR mechanism. SACs, in a way, bridge the gap between metal complexes, i.e., homogeneous catalysis, with the bulk heterogeneous catalysts. The single-atom nature of these material allows for much larger mass activities, addressing the issues of atom economy so critical for the transfer to the industry. The SACs concept was introduced not without problems of its own: to avoid the formation of nanoparticles, different synthetic routes were studied but, generally, it is still difficult to obtain high metal loadings without nanoparticles' formation, with notable exceptions [66]. In this landscape, carbon-based material arose as a natural support structure, given the low price, ease of functionalization, and ability to stabilize TM atoms thanks to heteroatom doping (e.g., TM- $\mathrm{N}_{4}$ structures) $[67,68]$.

Many of these solutions, however, are not as compelling as a first glance would suggest: to ensure the atomic dispersion, SACs loading is often lower than $1 \%$ [69-72] because the single atoms, as their loading increases, usually have a higher tendency to stick together and form clusters or even nanoparticles. This low density of catalytic sites is sometimes obscured using TM mass normalized activities. Even if these metrics are useful to highlight the boosted activity of SACs with respect to bulk or even nanoscale materials, most often it is difficult to have meaningful comparisons with non-metal catalysts. As an example, the figures of merit cited previously and reported by Lv et al. $\left(8.09 \mathrm{\mu g} \mathrm{h}^{-1} \mathrm{mg}_{\mathrm{cat}}{ }^{-1}\right.$ for defective carbon nitride) [41] and Wang et al. (1305 $\mathrm{g} \mathrm{h} \mathrm{h}^{-1} \mathrm{mg}_{\mathrm{Au}}{ }^{-1}$ for Au single-atom supported on carbon nitride) [42] are in fact very similar, given the low Au amount of $0.15 \%$ on the SAC (see Table 1 for a more meaningful comparison).

To address the loading limits, an approach involving double-atom catalysts (DACs) was first proposed. These materials can be homometallic or heterometallic in nature $\left(\mathrm{TM}_{2}\right.$ or $\mathrm{TM}^{1}-\mathrm{TM}^{2}$ ) and principally differ on how the two $\mathrm{TM}$ are fixed on the support: Some catalysts show direct bonding between two metallic atoms, working as a single active site 
for the reaction of interest. Others have the two different atoms "singularly" stabilized on the underlying structure, relying on a more synergistic effect between the two active sites [73,74]. Moreover, recent papers suggest the possibility of triple- or even quadrupleatom catalysts $[75,76]$. These solutions have been investigated as a way to further augment the density of the TM sites on the support, and are, as of now, mainly in the theoretical stage. The big challenge is, then, to prepare a high-loading catalyst in precise atomic form, pinpointing the activity to the peculiar structure of the catalytic site.

\section{The Advantage of Single to Multiple Atoms}

Carbon-supported SACs currently represent the most widely studied material of the NRR catalyst family in experimental papers. This is possibly due to assessed synthetic routes already in place [7] based on a decade of research stemming from the first seminal work [77]. Zeng et al. synthetized a material based on ruthenium single atoms supported on N-doped carbon [43]. To ensure the retention of the single-atom nature, the Ru salt was adsorbed on the porous structure of ZIF-8 (Figure 4). After pyrolysis, the obtained material had a Ru loading of $0.18 \%$ and displayed a record activity of $120.9 \mu \mathrm{g} \mathrm{h}^{-1} \mathrm{mg}_{\mathrm{cat}^{-1}}$ at $-0.2 \mathrm{~V}$, with $29 \%$ selectivity toward NRR in in $0.05 \mathrm{M} \mathrm{H}_{2} \mathrm{SO}_{4}$ (Table 1).

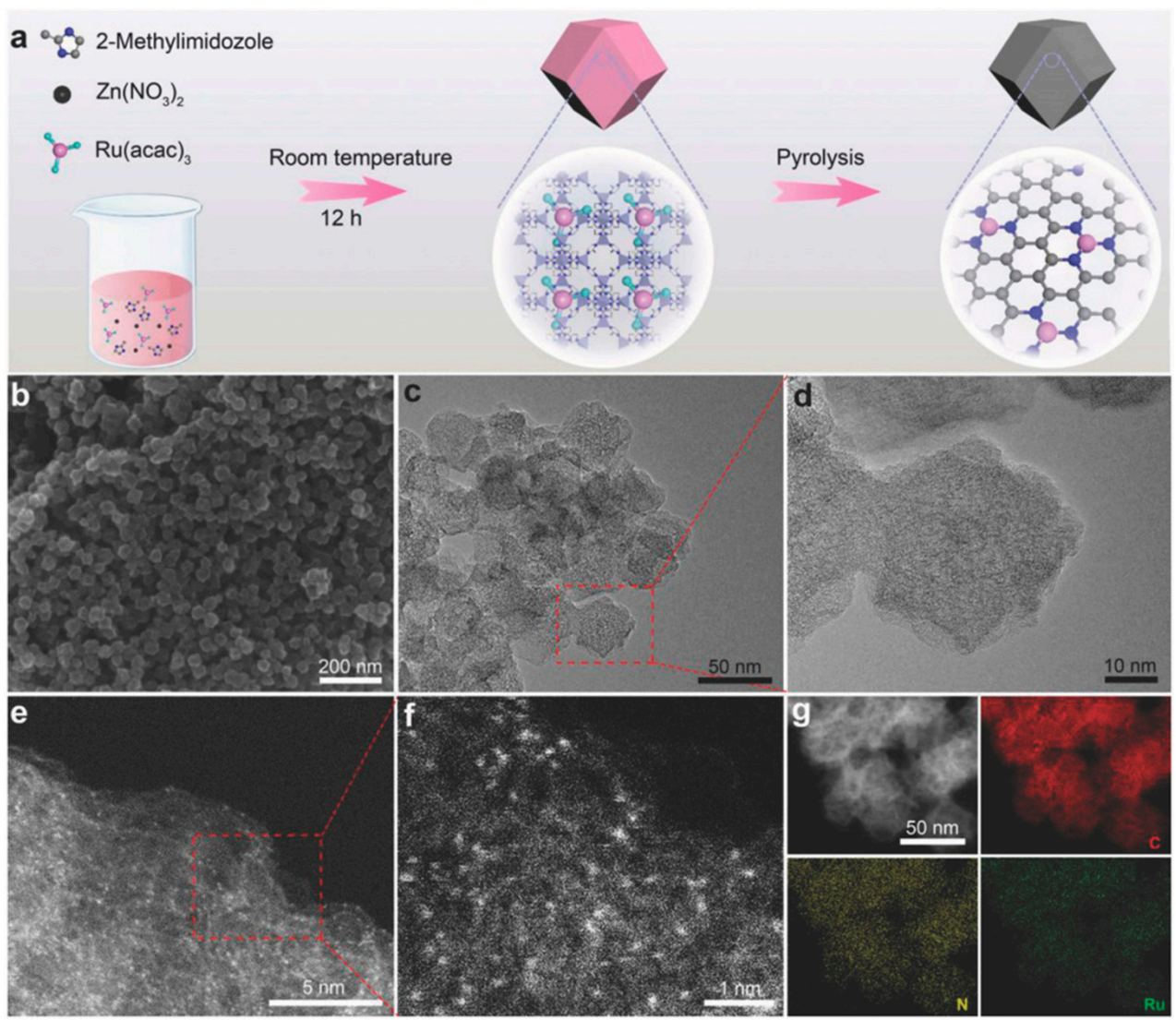

Figure 4. (a) Scheme of the synthetic procedure for Ru SAs/N-C. (b) A typical SEM image, (c) TEM image, (d) magnified TEM image, (e) HAADF-STEM image, and (f) magnified HAADF-STEM image of Ru SAs/N-C. (g) HAADF-STEM image and corresponding EDS elemental mapping results for $\mathrm{Ru}$ SAs/N-C. Reprinted with the permission from [43]. Copyright 2018 Wiley- WHC Verlag and Co. KGaA Weinheim.

By using $\mathrm{N}_{2}$-TPD (temperature-programmed desorption) analysis and theoretical calculations, the authors concluded that Ru SAs/N-C facilitated the adsorption of ${ }^{*} \mathrm{~N}_{2}$, and the $\Delta G$ value for $N_{2}$ dissociation on $R u_{1}-N_{3}$ and $R u_{1}-N_{4}$ moieties is lower than that on $\mathrm{Ru}$ (101), which results in enhanced NRR activity. Regarding earth-abundant metals, the most explored solutions are Fe- and Mo-based materials, inspired by natural 
nitrogenase enzymes. In particular, Han et al. explored the activity of atomically dispersed molybdenum on NC obtained by pyrolysis of glucose and hydroxylamine in the presence of ammonium molybdate [44]. This synthesis resulted in a very high metal loading of $9.5 \%$ without the formation of metal clusters/nanoparticles or amorphous carbon. The catalyst activity was evaluated to be $34.0 \mu \mathrm{g} \mathrm{h}^{-1} \mathrm{mg}_{\text {cat }}{ }^{-1}$, with $14.6 \%$ selectivity at $-0.3 \mathrm{~V}$ in $0.1 \mathrm{M} \mathrm{KOH}$. Lü et al. anchored Fe single atoms on $\mathrm{N}_{4}$ moieties on a N-doped carbon framework [45]. The relatively high loading (4.2\%) was possible thanks to its synthesis, in which a modified ZIF-8 structure (with Zn and Fe nodes) was pyrolyzed. After acid leaching, the resulting porous structure was tested for NRR with a rate of $62.9 \mu \mathrm{g} \mathrm{h}^{-1} \mathrm{mg}_{\text {cat }}{ }^{-1}$ and a selectivity of $18.6 \%$ at $-0.4 \mathrm{~V}$ in $1 \mathrm{M}$ PBS solution. Finally, Wang et al. synthetized a Fe-based SAC supported on N-doped graphene sheets with a very low overpotential for NRR [46]. Shifting the start of nitrogen fixation to higher potentials, this material exhibited a FE of $56 \%$ at $0 \mathrm{~V}$ thanks to little competition of HER. The $\mathrm{NH}_{3}$ rate of formation, however, turned out to be modest $\left(7.48 \mu \mathrm{g} \mathrm{h}^{-1} \mathrm{mg}_{\text {cat }}{ }^{-1}\right)$ due to the low currents at this potential (see Table 1 for data comparison). Many more materials have been studied in theoretical works based on different transition metals and many supports [78-80]. Even more interestingly, a lot of computational papers explored the differences in binding energies between SACs and DACs [81-83]. Chen et al. [81] compared $\mathrm{SACs} / \mathrm{C}_{2} \mathrm{~N}$ to homonuclear DACs $/ \mathrm{C}_{2} \mathrm{~N}$, finding that the energetics involved in NRR seems more favorable on DACs in all the cases taken into consideration. In particular, $\mathrm{Mn}_{2} / \mathrm{C}_{2} \mathrm{~N}$ showed preferred adsorption of $\mathrm{N}_{2}$ compared with proton and $\mathrm{H}_{2} \mathrm{O}$ and, in so doing, suppressing HER. Arachchige et al. [83] again compared SACs and DACs, this time supported on graphene (GY), and $\mathrm{Ru}_{2} @ G Y$ stood out as the best catalyst for $\mathrm{N}_{2}$ reduction via the enzymatic pathway. Moreover, the study suggested that the DAC TM catalysts might offer much better performance in catalyzing multiple-step reactions, such as NRR, penalizing the simple HER process. Many additional computational studies have focused on the exploration of DACs' stability and applicability as NRR catalysts [84-89], looking at both homonuclear and heteronuclear examples. However, in recent years, even DACs have been overshadowed, as scientists have started to consider the theoretical possibilities with higher numbers of neighboring active atom catalysts. Ma et al. [90], for example, compared energetics over $\mathrm{TM}_{\mathrm{x}}-\mathrm{GY}(\mathrm{x}=1-3$ and $\mathrm{TM}=\mathrm{Mn}, \mathrm{Fe}, \mathrm{Co}$, and $\mathrm{Ni})$ homometallic materials and found that these TACs were not able to absorb and activate $\mathrm{N}_{2}{ }^{*}$. Finally, Li et al. [76] considered Mo species supported on graphene from $\mathrm{Mo}_{1} @$ GDY to $\mathrm{Mo}_{4} @ G D Y$ (Figure 5), noting that for some energetic parameters, $\mathrm{Mo}_{3} @$ GDY showed better performances than the single-atom species, with a predicted onset potential of only $-0.32 \mathrm{~V}$.

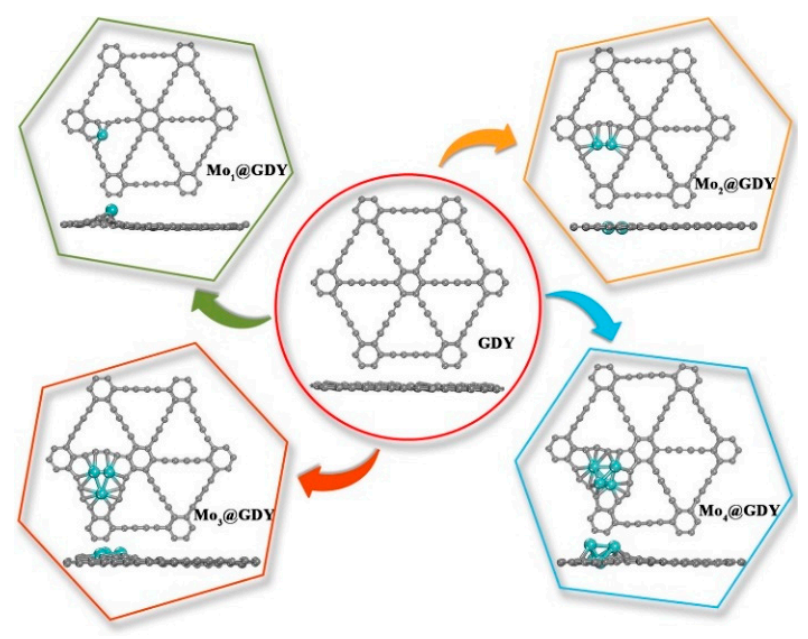

Figure 5. Simulated structures for GDY and Mo @GDY from a planar and vertical view. Reprinted with permission from [76]. Copyright 2021 American Chemical Society. 


\section{Guidelines to Future Approaches}

As pointed out mainly in Sections 4 and 5 , until now, the majority of new studies on NRR electrocatalysts with atomic features have been based on theoretical studies rather than experimental approaches, which therefore leaves a void in the state-of-the-art regarding the two issues of new carbon-based electrocatalysts: their synthesis and characterization.

According to the fundamental information collected by the computational approach, here, we attempt to set useful guidelines for future developments to fill the gap between theory and practice. Among the variety of transition metals and carbon support structures adopted, the following common targets have predominantly emerged.

First, the role of carbon structures has not been restricted only to a simple conductive support, but according to the improved structural specificities (i.e., presence of single or multiple doping atoms), has a direct role in the electrocatalysis process. In the future, it will be imperative to find the precursors whose resulting "carbons" will have the best textural and chemical characteristics—such as porosity, defects, and dopants, as well as exploiting the nanoscale structuring - in order to maximize NRR activity.

Second, the synergy between the transition metal component and the carbon texture should be based on the rational distribution of the electrocatalytic centers obtainable from both an atomic-scale design but also from its adequate concentration on the catalysts surface. The combined structural properties of both affect the NRR reaction mechanism and consequently NRR efficiency.

Third, to assist an NRR catalyst toward high selectivity, the availability of the proton can be manipulated to limit the occurrence of the HER. Catalyst structures/features (i.e., defects, edges, and steps) and/or catalyst-electrolyte combinations should provide the right pathways to promote high selectivity and better efficiency.

Finally, taking into account the insights of computational investigations, including DFT free energy calculations for different surface structures and several attempts to understand the NRR reaction mechanism, a fundamental future step will be the translation to applicative studies of atomic-scale materials. The few papers on double-atom catalyst design show great promise in these types of materials, but it is important to introduce new synthetic methods to obtain such kind of structures. Computational studies have also suggested the stability of these materials and yet, given the intricacies of the nitrogen reduction reaction, it is critical to assess their continued activity against poisoning, breakage, and deactivation.

Author Contributions: Conceptualization, M.F., M.B. and M.M. Writing — original draft preparation, M.F. and M.B. Writing - review and editing, M.B., M.M. and P.F. Funding acquisition, P.F. All authors have read and agreed to the published version of the manuscript.

Funding: This research was funded by the University of Trieste grant number FRA2021.

Acknowledgments: M.M. kindly acknowledges the funding scheme FRA2021 from the University of Trieste.

Conflicts of Interest: The authors declare no conflict of interest.

\section{References}

1. Smil, V. Detonator of the Population Explosion. Nature 1999, 400, 415. [CrossRef]

2. Industrial Ammonia Production Emits More $\mathrm{CO}_{2}$ Than Any Other Chemical-Making Reaction. Chemists Want to Change That. Available online: https://cen.acs.org/environment/green-chemistry/Industrial-ammonia-production-emits-CO2/97/i24 (accessed on 9 October 2021).

3. Chu, S.; Cui, Y.; Liu, N. The Path towards Sustainable Energy. Nat. Mater. 2016, 16, 16-22. [CrossRef] [PubMed]

4. Vojvodic, A.; Medford, A.J.; Studt, F.; Abild-Pedersen, F.; Khan, T.S.; Bligaard, T.; Nørskov, J.K. Exploring the Limits: A Low-Pressure, Low-Temperature Haber-Bosch Process. Chem. Phys. Lett. 2014, 598, 108-112. [CrossRef]

5. Rouwenhorst, K.H.R.; van der Ham, A.G.J.; Lefferts, L. Beyond Haber-Bosch: The Renaissance of the Claude Process. Int. J. Hydrogen Energy 2021, 46, 21566-21579. [CrossRef] 
6. Fúnez Guerra, C.; Reyes-Bozo, L.; Vyhmeister, E.; Jaén Caparrós, M.; Salazar, J.L.; Clemente-Jul, C. Technical-Economic Analysis for a Green Ammonia Production Plant in Chile and Its Subsequent Transport to Japan. Renew. Energy 2020, 157, $404-414$. [CrossRef]

7. Chen, Y.; Ji, S.; Chen, C.; Peng, Q.; Wang, D.; Li, Y. Single-Atom Catalysts: Synthetic Strategies and Electrochemical Applications. Joule 2018, 2, 1242-1264. [CrossRef]

8. Qichen Wang; Yongpeng Lei; Dingsheng Wang; Yadong Li Defect Engineering in Earth-Abundant Electrocatalysts for $\mathrm{CO}_{2}$ and $\mathrm{N}_{2}$ Reduction. Energy Environ. Sci. 2019, 12, 1730-1750. [CrossRef]

9. Iglesias, D.; Giuliani, A.; Melchionna, M.; Marchesan, S.; Criado, A.; Nasi, L.; Bevilacqua, M.; Tavagnacco, C.; Vizza, F.; Prato, M.; et al. N-Doped Graphitized Carbon Nanohorns as a Forefront Electrocatalyst in Highly Selective $\mathrm{O}_{2}$ Reduction to $\mathrm{H}_{2} \mathrm{O}_{2}$. Chem 2018, 4, 106-123. [CrossRef]

10. Melchionna, M.; Fornasiero, P.; Prato, M. The Rise of Hydrogen Peroxide as the Main Product by Metal-Free Catalysis in Oxygen Reductions. Adv. Mater. 2019, 31, 1802920. [CrossRef]

11. Duan, X.; Xu, J.; Wei, Z.; Ma, J.; Guo, S.; Wang, S.; Liu, H.; Dou, S. Metal-Free Carbon Materials for $\mathrm{CO}_{2}$ Electrochemical Reduction. Adv. Mater. 2017, 29, 1701784. [CrossRef]

12. Wu, J.; Ma, S.; Sun, J.; Gold, J.I.; Tiwary, C.; Kim, B.; Zhu, L.; Chopra, N.; Odeh, I.N.; Vajtai, R.; et al. A Metal-Free Electrocatalyst for Carbon Dioxide Reduction to Multi-Carbon Hydrocarbons and Oxygenates. Nat. Commun. 2016, 7, 1-6. [CrossRef]

13. Tuci, G.; Zafferoni, C.; D’Ambrosio, P.; Caporali, S.; Ceppatelli, M.; Rossin, A.; Tsoufis, T.; Innocenti, M.; Giambastiani, G. Tailoring Carbon Nanotube N-Dopants While Designing Metal-Free Electrocatalysts for the Oxygen Reduction Reaction in Alkaline Medium. ACS Catal. 2013, 3, 2108-2111. [CrossRef]

14. Zhang, X.; Yao, S.; Chen, P.; Wang, Y.; Lyu, D.; Yu, F.; Qing, M.; Tian, Z.Q.; Shen, P.K. Revealing the Dependence of Active Site Configuration of N Doped and N, S-Co-Doped Carbon Nanospheres on Six-Membered Heterocyclic Precursors for Oxygen Reduction Reaction. J. Catal. 2020, 389, 677-689. [CrossRef]

15. You, C.; Liao, S.; Li, H.; Hou, S.; Peng, H.; Zeng, X.; Liu, F.; Zheng, R.; Fu, Z.; Li, Y. Uniform Nitrogen and Sulfur Co-Doped Carbon Nanospheres as Catalysts for the Oxygen Reduction Reaction. Carbon 2014, 69, 294-301. [CrossRef]

16. Zhang, Y.; Zhuang, X.; Su, Y.; Zhang, F.; Feng, X. Polyaniline Nanosheet Derived B/N Co-Doped Carbon Nanosheets as Efficient Metal-Free Catalysts for Oxygen Reduction Reaction. J. Mater. Chem. A 2014, 2, 7742-7746. [CrossRef]

17. Chen, C.; Sun, X.; Yan, X.; Wu, Y.; Liu, H.; Zhu, Q.; Bediako, B.B.A.; Han, B. Boosting $\mathrm{CO}_{2}$ Electroreduction on N,P-Co-Doped Carbon Aerogels. Angew. Chem. Int. Ed. 2020, 59, 11123-11129. [CrossRef]

18. Park, C.; Jung, H.; You, J.; Park, H.; Yu, Y.; Lee, S.; Jang, K.; Na, S. Enhancement of Electrode Performance through Surface Modification Using Carbon Nanotubes and Porous Gold Nanostructures. Nanotechnology 2021, 32, 505502. [CrossRef]

19. Francke, M.; Hermann, H.; Wenzel, R.; Seifert, G.; Wetzig, K. Modification of Carbon Nanostructures by High Energy Ball-Milling under Argon and Hydrogen Atmosphere. Carbon 2005, 43, 1204-1212. [CrossRef]

20. Majumder, M.; Saini, H.; Dědek, I.; Schneemann, A.; Chodankar, N.R.; Ramarao, V.; Santosh, M.S.; Nanjundan, A.K.; Kment, Š.; Dubal, D.; et al. Rational Design of Graphene Derivatives for Electrochemical Reduction of Nitrogen to Ammonia. ACS Nano 2021, 15, 17275-17298. [CrossRef]

21. Ong, W.-J.; Kurnianditia Putri, L.; Tan, Y.-C.; Tan, L.-L.; Li, N.; Hau Ng, Y.; Wen, X.; Chai, S.-P.; Berlin, S.-V. Unravelling Charge Carrier Dynamics in Protonated G- $\mathrm{C}_{3} \mathrm{~N}_{4}$ Interfaced with Carbon Nanodots as Co-Catalysts toward Enhanced Photocatalytic $\mathrm{CO}_{2}$ Reduction: A Combined Experimental and First-Principles DFT Study. Nano Res. 2017, 10, 1673-1696. [CrossRef]

22. Yadav, R.M.; Li, Z.; Zhang, T.; Sahin, O.; Roy, S.; Gao, G.; Guo, H.; Vajtai, R.; Wang, L.; Ajayan, P.M.; et al. Amine-Functionalized Carbon Nanodot Electrocatalysts Converting Carbon Dioxide to Methane. Adv. Mater. 2021, 2105690. [CrossRef]

23. Martínez-Periñán, E.; Bravo, I.; Rowley-Neale, S.J.; Lorenzo, E.; Banks, C.E. Carbon Nanodots as Electrocatalysts towards the Oxygen Reduction Reaction. Electroanalysis 2018, 30, 436-444. [CrossRef]

24. Andersen, S.Z.; Čolić, V.; Yang, S.; Schwalbe, J.A.; Nielander, A.C.; McEnaney, J.M.; Enemark-Rasmussen, K.; Baker, J.G.; Singh, A.R.; Rohr, B.A.; et al. A Rigorous Electrochemical Ammonia Synthesis Protocol with Quantitative Isotope Measurements. Nature 2019, 570, 504-508. [CrossRef]

25. Ferrara, M.; Bevilacqua, M.; Tavagnacco, C.; Vizza, F.; Fornasiero, P. Fast Screening Method for Nitrogen Reduction Reaction (NRR) Electrocatalytic Activity with Rotating Ring-Disc Electrode (RRDE) Analysis in Alkaline Environment. ChemCatChem 2020, 12, 6205-6213. [CrossRef]

26. Greenlee, L.F.; Renner, J.N.; Foster, S.L. The Use of Controls for Consistent and Accurate Measurements of Electrocatalytic Ammonia Synthesis from Dinitrogen. ACS Catal. 2018, 8, 7820-7827. [CrossRef]

27. Chen, G.-F.; Ren, S.; Zhang, L.; Cheng, H.; Luo, Y.; Zhu, K.; Ding, L.-X.; Wang, H. Advances in Electrocatalytic $\mathrm{N}_{2}$ ReductionStrategies to Tackle the Selectivity Challenge. Small Methods 2019, 3, 1800337. [CrossRef]

28. Mukherjee, S.; Cullen, D.A.; Karakalos, S.; Liu, K.; Zhang, H.; Zhao, S.; Xu, H.; More, K.L.; Wang, G.; Wu, G. Metal-Organic Framework-Derived Nitrogen-Doped Highly Disordered Carbon for Electrochemical Ammonia Synthesis Using $\mathrm{N}_{2}$ and $\mathrm{H}_{2} \mathrm{O}$ in Alkaline Electrolytes. Nano Energy 2018, 48, 217-226. [CrossRef]

29. Song, Y.; Johnson, D.; Peng, R.; Hensley, D.K.; Bonnesen, P.V.; Liang, L.; Huang, J.; Yang, F.; Zhang, F.; Qiao, R.; et al. A Physical Catalyst for the Electrolysis of Nitrogen to Ammonia. Sci. Adv. 2018, 4, e1700336. [CrossRef]

30. Xie, J.; Dong, H.; Cao, X.; Li, Y. Computational Insights into Nitrogen Reduction Reaction Catalyzed by Transition Metal Doped Graphene: Comparative Investigations. Mater. Chem. Phys. 2020, 243, 122622. [CrossRef] 
31. Wen, Y.; Zhu, H.; Hao, J.; Lu, S.; Zong, W.; Lai, F.; Ma, P.; Dong, W.; Liu, T.; Du, M. Metal-Free Boron and Sulphur Co-Doped Carbon Nanofibers with Optimized p-Band Centers for Highly Efficient Nitrogen Electroreduction to Ammonia. Appl. Catal. B Environ. 2021, 292, 120144. [CrossRef]

32. Kirk, C.; Chen, L.D.; Siahrostami, S.; Karamad, M.; Bajdich, M.; Voss, J.; Nørskov, J.K.; Chan, K. Theoretical Investigations of the Electrochemical Reduction of CO on Single Metal Atoms Embedded in Graphene. ACS Cent. Sci. 2017, 3, 1286-1293. [CrossRef] [PubMed]

33. Jiang, K.; Siahrostami, S.; Akey, A.J.; Li, Y.; Lu, Z.; Lattimer, J.; Hu, Y.; Stokes, C.; Gangishetty, M.; Chen, G.; et al. Transition-Metal Single Atoms in a Graphene Shell as Active Centers for Highly Efficient Artificial Photosynthesis. Chem 2017, 3, 950-960. [CrossRef]

34. Siahrostami, S.; Jiang, K.; Karamad, M.; Chan, K.; Wang, H.; Nørskov, J. Theoretical Investigations into Defected Graphene for Electrochemical Reduction of $\mathrm{CO}_{2}$. ACS Sustain. Chem. Eng. 2017, 5, 11080-11085. [CrossRef]

35. Shi, L.; Yin, Y.; Wang, S.; Sun, H. Rational Catalyst Design for $\mathrm{N}_{2}$ Reduction under Ambient Conditions: Strategies toward Enhanced Conversion Efficiency. ACS Catal. 2020, 10, 6870-6899. [CrossRef]

36. Zhang, M.; Choi, C.; Huo, R.; Gu, G.H.; Hong, S.; Yan, C.; Xu, S.; Robertson, A.W.; Qiu, J.; Jung, Y.; et al. Reduced Graphene Oxides with Engineered Defects Enable Efficient Electrochemical Reduction of Dinitrogen to Ammonia in Wide PH Range. Nano Energy 2020, 68, 104323. [CrossRef]

37. Xia, L.; Yang, J.; Wang, H.; Zhao, R.; Chen, H.; Fang, W.; Asiri, A.M.; Xie, F.; Cui, G.; Sun, X. Sulfur-Doped Graphene for Efficient Electrocatalytic $\mathrm{N}_{2}$-to- $\mathrm{NH}_{3}$ Fixation. Chem. Commun. 2019, 55, 3371-3374. [CrossRef]

38. Zhou, F.; Azofra, L.M.; Ali, M.; Kar, M.; Simonov, A.N.; McDonnell-Worth, C.; Sun, C.; Zhang, X.; Macfarlane, D.R. ElectroSynthesis of Ammonia from Nitrogen at Ambient Temperature and Pressure in Ionic Liquids. Energy Environ. Sci. 2017, 10, 2516-2520. [CrossRef]

39. Yu, X.; Han, P.; Wei, Z.; Huang, L.; Gu, Z.; Peng, S.; Ma, J.; Zheng, G. Boron-Doped Graphene for Electrocatalytic $\mathrm{N}_{2}$ Reduction. Joule 2018, 2, 1610-1622. [CrossRef]

40. Liu, Y.; Li, Q.; Guo, X.; Kong, X.; Ke, J.; Chi, M.; Li, Q.; Geng, Z.; Zeng, J. A Highly Efficient Metal-Free Electrocatalyst of F-Doped Porous Carbon toward $\mathrm{N}_{2}$ Electroreduction. Adv. Mater. 2020, 32, 1907690. [CrossRef]

41. Lv, C.; Qian, Y.; Yan, C.; Ding, Y.; Liu, Y.; Chen, G.; Yu, G. Defect Engineering Metal-Free Polymeric Carbon Nitride Electrocatalyst for Effective Nitrogen Fixation under Ambient Conditions. Angew. Chem. Int. Ed. 2018, 57, 10246-10250. [CrossRef]

42. Wang, X.; Wang, W.; Qiao, M.; Wu, G.; Chen, W.; Yuan, T.; Xu, Q.; Chen, M.; Zhang, Y.; Wang, X.; et al. Atomically Dispersed Au 1 Catalyst towards Efficient Electrochemical Synthesis of Ammonia. Sci. Bull. 2018, 63, 1246-1253. [CrossRef]

43. Geng, Z.; Liu, Y.; Kong, X.; Li, P.; Li, K.; Liu, Z.; Du, J.; Shu, M.; Si, R.; Zeng, J. Achieving a Record-High Yield Rate of 120.9 for N 2 Electrochemical Reduction over Ru Single-Atom Catalysts. Adv. Mater. 2018, 30, 1803498. [CrossRef]

44. Han, L.; Liu, X.; Chen, J.; Lin, R.; Liu, H.; Lü, F.; Bak, S.; Liang, Z.; Zhao, S.; Stavitski, E.; et al. Atomically Dispersed Molybdenum Catalysts for Efficient Ambient Nitrogen Fixation. Angew. Chem. Int. Ed. 2019, 58, 2321-2325. [CrossRef]

45. Lü, F.; Zhao, S.; Guo, R.; He, J.; Peng, X.; Bao, H.; Fu, J.; Han, L.; Qi, G.; Luo, J.; et al. Nitrogen-Coordinated Single Fe Sites for Efficient Electrocatalytic $\mathrm{N}_{2}$ Fixation in Neutral Media. Nano Energy 2019, 61, 420-427. [CrossRef]

46. Wang, M.; Liu, S.; Qian, T.; Liu, J.; Zhou, J.; Ji, H.; Xiong, J.; Zhong, J.; Yan, C. Over 56.55\% Faradaic Efficiency of Ambient Ammonia Synthesis Enabled by Positively Shifting the Reaction Potential. Nature Communications 2019, 10, 1-8. [CrossRef]

47. Zheng, J.; Jiang, L.; Lyu, Y.; Jian, S.P.; Wang, S. Green Synthesis of Nitrogen-to-Ammonia Fixation: Past, Present, and Future. Energy Environ. Mater. 2021. [CrossRef]

48. Xu, H.; Ma, L.; Jin, Z. Nitrogen-Doped Graphene: Synthesis, Characterizations and Energy Applications. J. Energy Chem. 2018, 27, 146-160. [CrossRef]

49. Bai, J.; Zhu, Q.; Lv, Z.; Dong, H.; Yu, J.; Dong, L. Nitrogen-Doped Graphene as Catalysts and Catalyst Supports for Oxygen Reduction in Both Acidic and Alkaline Solutions. Int. J. Hydrogen Energy 2013, 38, 1413-1418. [CrossRef]

50. Wang, Y.; Shao, Y.; Matson, D.W.; Li, J.; Lin, Y. Nitrogen-Doped Graphene and Its Application in Electrochemical Biosensing. ACS Nano 2010, 4, 1790-1798. [CrossRef]

51. Rao, C.N.R.; Gopalakrishnan, K.; Govindaraj, A. Synthesis, Properties and Applications of Graphene Doped with Boron, Nitrogen and Other Elements. Nano Today 2014, 9, 324-343. [CrossRef]

52. Zhang, Y.; Melchionna, M.; Medved, M.; Błoński, P.; Steklý, T.; Bakandritsos, A.; Kment, Š.; Zbořil, R.; Otyepka, M.; Fornaserio, P.; et al. Enhanced On-Site Hydrogen Peroxide Electrosynthesis by a Selectively Carboxylated N-Doped Graphene Catalyst. ChemCatChem 2021, 13, 4372-4383. [CrossRef]

53. Zhang, Y.; Ge, J.; Wang, L.; Wang, D.; Ding, F.; Tao, X.; Chen, W. Manageable N-Doped Graphene for High Performance Oxygen Reduction Reaction. Sci. Rep. 2013, 3, 1-8. [CrossRef]

54. Deng, B.; Wang, D.; Jiang, Z.; Zhang, J.; Shi, S.; Jiang, Z.J.; Liu, M. Amine Group Induced High Activity of Highly Torn Amine Functionalized Nitrogen-Doped Graphene as the Metal-Free Catalyst for Hydrogen Evolution Reaction. Carbon 2018, 138, 169-178. [CrossRef]

55. Yuan, J.; Zhi, W.Y.; Liu, L.; Yang, M.P.; Wang, H.; Lu, J.X. Electrochemical Reduction of $\mathrm{CO}_{2}$ at Metal-Free N-Functionalized Graphene Oxide Electrodes. Electrochim. Acta 2018, 282, 694-701. [CrossRef]

56. Le, Y.-Q.; Gu, J.; Tian, W.Q. Nitrogen-Fixation Catalyst Based on Graphene: Every Part Counts. Chem. Commun. 2014, 50, 13319-13322. [CrossRef] 
57. Zhu, J.; Xiao, P.; Li, H.; Carabineiro, S.A.C. Graphitic Carbon Nitride: Synthesis, Properties, and Applications in Catalysis. ACS Appl. Mater. Interfaces 2014, 6, 16449-16465. [CrossRef]

58. Zhang, J.; Chen, Y.; Wang, X. Two-Dimensional Covalent Carbon Nitride Nanosheets: Synthesis, Functionalization, and Applications. Energy Environ. Sci. 2015, 8, 3092-3108. [CrossRef]

59. Longobardo, F.; Filippini, G.; Forster, L.; Criado, A.; di Carmine, G.; Nasi, L.; D’Agostino, C.; Melchionna, M.; Fornasiero, P.; Prato, M. Light-Driven, Heterogeneous Organocatalysts for C-C Bond Formation toward Valuable Perfluoroalkylated Intermediates. Sci. Adv. 2020, 6, eabc9923. [CrossRef]

60. Lin, L.; Ou, H.; Zhang, Y.; Wang, X. Tri-s-Triazine-Based Crystalline Graphitic Carbon Nitrides for Highly Efficient Hydrogen Evolution Photocatalysis. ACS Catal. 2016, 6, 3921-3931. [CrossRef]

61. Ghosh, I.; Khamrai, J.; Savateev, A.; Shlapakov, N.; Antonietti, M.; König, B. Organic Semiconductor Photocatalyst Can Bifunctionalize Arenes and Heteroarenes. Science 2019, 365, 360-366. [CrossRef]

62. Zheng, Y.; Jiao, Y.; Zhu, Y.; Li, L.H.; Han, Y.; Chen, Y.; Du, A.; Jaroniec, M.; Qiao, S.Z. Hydrogen Evolution by a Metal-Free Electrocatalyst. Nat. Commun. 2014, 5, 3783. [CrossRef] [PubMed]

63. Wang, Y.; Liu, L.; Ma, T.; Zhang, Y.; Huang, H.; Wang, Y.H.; Liu, L.Z.; Zhang, Y.H.; Huang, H.W.; Ma, T.Y. 2D Graphitic Carbon Nitride for Energy Conversion and Storage. Adv. Funct. Mater. 2021, 31, 2102540. [CrossRef]

64. Chen, Z.; Zhao, J.; Cabrera, C.R.; Chen, Z. Computational Screening of Efficient Single-Atom Catalysts Based on Graphitic Carbon Nitride $\left(\mathrm{g}-\mathrm{C}_{3} \mathrm{~N}_{4}\right)$ for Nitrogen Electroreduction. Small Methods 2019, 3, 1800368. [CrossRef]

65. Wang, Z.; Yu, Z.; Zhao, J. Computational Screening of a Single Transition Metal Atom Supported on the $\mathrm{C}_{2} \mathrm{~N}$ Monolayer for Electrochemical Ammonia Synthesis. Phys. Chem. Chem. Phys. 2018, 20, 12835-12844. [CrossRef]

66. Shen, R.; Chen, W.; Peng, Q.; Lu, S.; Zheng, L.; Cao, X.; Wang, Y.; Zhu, W.; Zhang, J.; Zhuang, Z.; et al. High-Concentration Single Atomic Pt Sites on Hollow $\mathrm{CuS}_{\mathrm{x}}$ for Selective $\mathrm{O}_{2}$ Reduction to $\mathrm{H}_{2} \mathrm{O}_{2}$ in Acid Solution. Chem 2019, 5, 2099-2110. [CrossRef]

67. Singh, H.K.; Kumar, P.; Waghmare, U.V. Theoretical Prediction of a Stable 2D Crystal of Vanadium Porphyrin: A Half-Metallic Ferromagnet. J. Phys. Chem. C 2015, 119, 25657-25662. [CrossRef]

68. Choi, W.I.; Jhi, S.H.; Kim, K.; Kim, Y.H. Divacancy-Nitrogen-Assisted Transition Metal Dispersion and Hydrogen Adsorption in Defective Graphene: A First-Principles Study. Phys. Rev. B Condens. Matter Mater. Phys. 2010, 81, 085441. [CrossRef]

69. Deng, D.; Chen, X.; Yu, L.; Wu, X.; Liu, Q.; Liu, Y.; Yang, H.; Tian, H.; Hu, Y.; Du, P.; et al. A Single Iron Site Confined in a Graphene Matrix for the Catalytic Oxidation of Benzene at Room Temperature. Sci. Adv. 2015, 1, e1500462. [CrossRef]

70. Wang, L.; Zhang, W.; Wang, S.; Gao, Z.; Luo, Z.; Wang, X.; Zeng, R.; Li, A.; Li, H.; Wang, M.; et al. Atomic-Level Insights in Optimizing Reaction Paths for Hydroformylation Reaction over Rh/CoO Single-Atom Catalyst. Nat. Commun. 2016, 7, 14036. [CrossRef]

71. Liu, P.; Zhao, Y.; Qin, R.; Mo, S.; Chen, G.; Gu, L.; Chevrier, D.M.; Zhang, P.; Guo, Q.; Zang, D.; et al. Photochemical Route for Synthesizing Atomically Dispersed Palladium Catalysts. Science 2016, 352, 797-801. [CrossRef]

72. Jones, J.; Xiong, H.; DeLaRiva, A.T.; Peterson, E.J.; Pham, H.; Challa, S.R.; Qi, G.; Oh, S.; Wiebenga, M.H.; Hernández, X.I.P.; et al. Thermally Stable Single-Atom Platinum-on-Ceria Catalysts via Atom Trapping. Science 2016, 353, 150-154. [CrossRef]

73. Yan, Y.; Cheng, H.; Qu, Z.; Yu, R.; Liu, F.; Ma, Q.; Zhao, S.; Hu, H.; Cheng, Y.; Yang, C.; et al. Recent Progress on the Synthesis and Oxygen Reduction Applications of Fe-Based Single-Atom and Double-Atom Catalysts. J. Mater. Chem. A 2021, 9, $19489-19507$. [CrossRef]

74. Zhang, S.; Wu, Y.; Zhang, Y.X.; Niu, Z. Dual-Atom Catalysts: Controllable Synthesis and Electrocatalytic Applications. Sci. China Chem. 2021, 64, 1908-1922. [CrossRef]

75. Chen, Z.W.; Chen, L.X.; Jiang, M.; Chen, D.; Wang, Z.L.; Yao, X.; Singh, C.V.; Jiang, Q. A Triple Atom Catalyst with Ultrahigh Loading Potential for Nitrogen Electrochemical Reduction. J. Mater. Chem. A 2020, 8, 15086-15093. [CrossRef]

76. Li, M.; Cui, Y.; Zhang, X.; Luo, Y.; Dai, Y.; Huang, Y. Screening a Suitable Mo Form Supported on Graphdiyne for Effectively Electrocatalytic $\mathrm{N}_{2}$ Reduction Reaction: From Atomic Catalyst to Cluster Catalyst. J. Phys. Chem. Lett. 2020, 11, 8128-8137. [CrossRef]

77. Qiao, B.; Wang, A.; Yang, X.; Allard, L.F.; Jiang, Z.; Cui, Y.; Liu, J.; Li, J.; Zhang, T. Single-Atom Catalysis of CO Oxidation Using $\mathrm{Pt}_{1} / \mathrm{FeO}_{\mathrm{x}}$. Nat. Chem. 2011, 3, 634-641. [CrossRef]

78. Mao, X.; Zhou, S.; Yan, C.; Zhu, Z.; Du, A. A Single Boron Atom Doped Boron Nitride Edge as a Metal-Free Catalyst for N 2 Fixation. Phys. Chem. Chem. Phys. 2019, 21, 1110-1116. [CrossRef]

79. Yao, X.; Chen, Z.W.; Wang, Y.R.; Lang, X.Y.; Zhu, Y.F.; Gao, W.; Jiang, Q. High-Loading Intrinsic Active Sites for Ammonia Synthesis Using Efficient Single-Atom Catalyst: 2D Tungsten-Porphyrin Sheet. Appl. Surf. Sci. 2020, 529, 147183. [CrossRef]

80. Zheng, M.; Xu, H.; Li, Y.; Ding, K.; Zhang, Y.; Sun, C.; Chen, W.; Lin, W. Electrocatalytic Nitrogen Reduction by Transition Metal Single-Atom Catalysts on Polymeric Carbon Nitride. J. Phys. Chem. C 2021, 125, 13880-13888. [CrossRef]

81. Chen, Z.W.; Yan, J.-M.; Jiang, Q. Single or Double: Which Is the Altar of Atomic Catalysts for Nitrogen Reduction Reaction? Small Methods 2019, 3, 1800291. [CrossRef]

82. Qian, Y.; Liu, Y.; Zhao, Y.; Zhang, X.; Yu, G. Single vs Double Atom Catalyst for $\mathrm{N}_{2}$ Activation in Nitrogen Reduction Reaction: A DFT Perspective. EcoMat 2020, 2, e12014. [CrossRef]

83. Arachchige, L.J.; Xu, Y.; Dai, Z.; Zhang, X.; Wang, F.; Sun, C. Theoretical Investigation of Single and Double Transition Metals Anchored on Graphyne Monolayer for Nitrogen Reduction Reaction. J. Phys. Chem. C 2020, 124, 15295-15301. [CrossRef] 
84. Yang, W.; Huang, H.; Ding, X.; Ding, Z.; Wu, C.; Gates, I.D.; Gao, Z. Theoretical Study on Double-Atom Catalysts Supported with Graphene for Electroreduction of Nitrogen into Ammonia. Electrochim. Acta 2020, 335, 135667. [CrossRef]

85. Wu, Y.; He, C.; Zhang, W. Novel Design Strategy of High Activity Electrocatalysts toward Nitrogen Reduction Reaction via Boron-Transition-Metal Hybrid Double-Atom Catalysts. ACS Appl. Mater. Interfaces 2021, 13, 47520-47529. [CrossRef]

86. Yongkang Xu; Zhewei Cai; Pan Du; Jiaxing Zhou; Yonghui Pan; Ping Wu; Chenxin Cai Taming the Challenges of Activity and Selectivity in the Electrochemical Nitrogen Reduction Reaction Using Graphdiyne-Supported Double-Atom Catalysts. J. Mater. Chem. A 2021, 9, 8489-8500. [CrossRef]

87. Kang, B.; Yuan, Y.; Lv, Y.; Ai, H.; Yong Lee, J. Synergistic Ultra-High Activity of Double B Doped Graphyne for Electrocatalytic Nitrogen Reduction. Chem. Eng. J. 2022, 428, 131318. [CrossRef]

88. Zheng, G.; Li, L.; Hao, S.; Zhang, X.; Tian, Z.; Chen, L. Double Atom Catalysts: Heteronuclear Transition Metal Dimer Anchored on Nitrogen-Doped Graphene as Superior Electrocatalyst for Nitrogen Reduction Reaction. Adv. Theory Simul. 2020, 3, 2000190. [CrossRef]

89. Wei, Z.; He, J.; Yang, Y.; Xia, Z.; Feng, Y.; Ma, J. Fe, V-Co-Doped $\mathrm{C}_{2} \mathrm{~N}$ for Electrocatalytic $\mathrm{N}_{2}$-to-NH $\mathrm{N}_{3}$ Conversion. J. Energy Chem. 2021, 53, 303-308. [CrossRef]

90. Ma, D.; Zeng, Z.; Liu, L.; Huang, X.; Jia, Y. Computational Evaluation of Electrocatalytic Nitrogen Reduction on TM Single-, Double-, and Triple-Atom Catalysts (TM = Mn, Fe, Co, Ni) Based on Graphdiyne Monolayers. J. Phys. Chem. C 2019, 123, 19066-19076. [CrossRef] 